\section{Growth of Seedling Asparagus Inoculated with Glomus fasciculatum and Phosphorus Supplementation}

\author{
Rhoda Burrows', F.L. Pfleger ${ }^{2}$, and Luther Waters, Jr. ${ }^{3}$ \\ University of Minnesota, St. Paul, MN 55108
}

Additional index words. Asparagus officinalis, Glomus fasciculatum, vesiculararbuscular mycorrhizae, phosphorus

\begin{abstract}
Asparagus offcinalis L. 'Mary Washington' seedlings inoculated with Glomus fasciculatum (Thaxter) Gerd. and Trappe emend. Walker and Koske showed increased growth after 9 weeks, compared with noninoculated plants. Phosphorus supplementation $\left(25 \mathrm{~g} \cdot \mathrm{m}^{-3}\right)$ increased seedling growth of inoculated and noninoculated plants throughout the 26 weeks of the experiment. However, after 9 weeks, there were no differences in growth of inoculated, non-P-supplemented plants and noninoculated, P-supplemented plants. Fern height, fern and crown weight, and bud numbers correlated positively to the percentage of $G$. fasciculatum root infection.
\end{abstract}

Vesicular-arbuscular mycorrhizae (VAM) benefit many plant species, including asparagus (Hayman, 1983; Miller et al., 1986). While observed effects appear to be due primarily to increased uptake of nutrients, particularly P (Rhodes and Gerdemann, 1980), other demonstrated benefits include increased resistance to disease, drought, and salinity (Allen and Cunningham, 1983; Dehne, 1982; Miller et al., 1986; Safir et al., 1971).

While field data are limited, increased growth of VAM-inoculated asparagus has been reported (Wacker et al., 1987). Recent greenhouse studies using various inoculation techniques and soil and fertilizer regimes have shown asparagus seedlings to be responsive to several VAM species. Mycorrhizal species that have increased seedling asparagus growth include Glomus versiforme, G. monosporus, G. etunicatum G. fasciculatum and G. mosseae (Chang, 1985; Daniels and Menge, 1981; Hussey et al., 1984; Plenchette et al., 1982). Inoculation methods have varied from application of VAM spores onto germinated seedlings (Daniels and Menge, 1981) to mixing infected roots/soil with the growth medium of germinating or transplanted asparagus seedlings (Chang, 1985; Hussey et al., 1984; Plenchette et al., 1982). Seedling growth was not monitored during the course of these experiments, except by Hussey et al. (1984). Generally, P in the growing medium was maintained at adequate levels throughout these experiments. We found no detailed studies of asparagus seedling growth response to VAM inoculation at more than one $\mathrm{P}$ level and over several

Received for publication 17 Mar. 1989. Paper no. 15968, of the Scientific Journal Series, Univ. of Minnesota Agricultural Experiment Station. The cost of publishing this paper was defrayed in part by the payment of page charges. Under postal regulations, this paper therefore must be hereby marked advertisement solely to indicate this fact.

${ }^{1}$ Research Fellow, Dept. of Horticultural Science. ${ }^{2}$ Professor, Dept. of Plant Pathology.

${ }^{3}$ Professor, Dept. of Horticultural Science. months. Furthermore, the interaction of $\mathrm{P}$ supplementation with initial mycorrhizae establishment in asparagus and its effects on seedling vigor and growth are not well-documented, although Chang (1985) found no decrease in mycorrhizal root infection at several different levels of $\mathrm{P}$ fertilization. The objectives of this study were to: 1) assess the effects of $G$. fasciculatum as influenced by $\mathrm{P}$ on early seedling growth and development of asparagus seedlings; and 2) assess correlation of infection levels with plant vigor as measured by fern height, fern and crown weight, and bud number. For more complete characterization, G. fasciculatum spore counts, analysis of root infection levels, and analyses of tissue and soil $P$ levels were included.

Experimental design was a $2 \times 2$ factorial with 12 replications, completely randomized. Treatments included plants with 0 or $25 \mathrm{~g} \mathrm{G}$. fasciculatum inoculum, with 0 or 25 $\mathrm{g} \mathrm{P} / \mathrm{m}^{3}$ as superphosphate $(19.4 \% \mathrm{P})$. Seeds of an improved selection of Asparagus offi$P$ supplementation at the time of seeding. cinalis 'Mary Washington' were soaked in aerated distilled water for 3 days at room temperature, then seeded on 1 Aug. 1986 into $375-\mathrm{ml}$ pots filled with a steam-pasteurized 1 soil (Normania loam) : 1 sand $(\mathrm{v} / \mathrm{v})$ medium. Analysis of the medium indicated a $7.6 \mathrm{pH}$ and a nutrient content (all mg.liter-1) of $3 \mathrm{~N},<1 \mathrm{P}, 1 \mathrm{~K}$, and $200 \mathrm{Ca}$ The G. fasciculatum inoculum, which consisted of root pieces, soil, and spores $(\approx 350$ per $25 \mathrm{~g}$ inoculum) collected from Allium cepa L. pot cultures, was placed $25 \mathrm{~mm}$ below the soil surface. Following emergence, the plants were fertilized biweekly with a solution of $200 \mathrm{mg} 96 \mathrm{~N}-0 \mathrm{P}-77 \mathrm{~K}\left(\mathrm{NH}_{4} \mathrm{NO}_{3}\right.$ $+\mathrm{KNO}_{3} /$ liter for 20 weeks, then weekly with $100 \mathrm{mg} 36 \mathrm{~N}-0 \mathrm{P}-39 \mathrm{~K}-29 \mathrm{Ca}\left(\mathrm{CaNO}_{3}+\right.$ $\mathrm{KNO}_{3}$ /liter for 6 weeks, at which time the experiment was terminated. The plants were grown in the greenhouse under natural daylight supplemented by $400-\mathrm{W}$ halogen lights (photon flux density $=115 \mathrm{~mol} \cdot \mathrm{s}^{-1} \cdot \mathrm{m}^{-2}$ ), $12 \mathrm{hr} /$ day. Daytime temperatures were 21 to $27 \mathrm{C}$ and at night $15.5 \mathrm{C}$ was maintained.

Total fern height of each plant was recorded about every 2 weeks. After 26 weeks, the plants were harvested and rinsed to remove soil. Fresh and dry weights of crowns and ferns were taken, and fern samples were pooled within each treatment for foliar nutrient analysis. Soil samples were also pooled within each treatment for $G$. fasciculatum spore counts and nutrient analyses. Twenty feeder roots from each plant were preserved in FAA (13 ml formalin :5 ml acetic acid : $200 \mathrm{ml} \mathrm{95 \%} \mathrm{ethanol)} \mathrm{and} \mathrm{used} \mathrm{to} \mathrm{determine}$ percent root infection by $G$. fasciculatum. The roots were then stained according to the method of Phillips and Hayman (1970), with the following modifications: the roots were soaked in $20 \% \mathrm{KOH}$ for $20 \mathrm{~min}$ at room temperature, acidified for 3 to $6 \mathrm{~min}$ in $10 \%$ $\mathrm{HCl}$, and stained in $0.1 \%$ Trypan blue in lactophenol for 15 to 20 rein, then destained in lactophenol. Ten $10-\mathrm{mm}$ root pieces from each of the 48 plants were mounted in lactophenol, and each piece was examined by

Table 1. Average asparagus fern height, as influenced by inoculation with Glomus fasciculatum and

\begin{tabular}{|c|c|c|c|c|c|c|c|}
\hline \multirow[b]{3}{*}{ Inoculation } & \multirow{3}{*}{$\begin{array}{c}P \\
\left(\mathrm{~g} \cdot \mathrm{m}^{-3}\right)\end{array}$} & \multicolumn{6}{|c|}{ Total average height $(\mathrm{cm} /$ plant $)$} \\
\hline & & \multicolumn{6}{|c|}{ Weeks after seeding ${ }^{z}$} \\
\hline & & 4 & 8 & 9 & 11 & 15 & 26 \\
\hline \multirow[t]{2}{*}{ Yes } & 25 & 20 & 53 & 76 & 97 & 149 & 194 \\
\hline & 0 & 15 & 34 & 55 & 79 & 133 & 168 \\
\hline \multirow[t]{2}{*}{ No } & 25 & 22 & 51 & 63 & 72 & 113 & 143 \\
\hline & 0 & 16 & 19 & 20 & 21 & 22 & 22 \\
\hline$S E^{y}$ & & 5.2 & 14.5 & 20.2 & 20.7 & 31.5 & 47.7 \\
\hline \multicolumn{8}{|l|}{ Significance } \\
\hline \multicolumn{2}{|c|}{ Inoculation main effect } & NS & NS & $* * *$ & $* * *$ & $* * *$ & $* * *$ \\
\hline \multicolumn{2}{|c|}{ P suppl, main effect } & $*$ & $* * *$ & $* * *$ & $* * *$ & $* * *$ & $* * *$ \\
\hline \multicolumn{2}{|l|}{ Inoc $\times P$} & NS & NS & NS & $*$ & $* * *$ & $* * *$ \\
\hline \multicolumn{2}{|c|}{ Inoc/P vs. inoc/no-P } & NS & $*$ & **** & $* * *$ & $* * *$ & $* * *$ \\
\hline \multicolumn{2}{|c|}{ Inoc/P vs. noninoc/P } & NS & NS & NS & $* *$ & $* *$ & $*$ \\
\hline \multicolumn{2}{|c|}{ Inoc/no $\mathrm{P}$ vs. noninoc/no $\mathrm{P}$} & NS & $*$ & $* * *$ & $* * *$ & $* * *$ & $* * *$ \\
\hline \multicolumn{2}{|c|}{ Inoc/no $\mathrm{P}$ vs. noninoc/P } & $*$ & $* *$ & NS & NS & NS & NS \\
\hline \multicolumn{2}{|c|}{ Inoc vs. noninoc/P } & $*$ & NS & NS & $*$ & $*$ & * \\
\hline \multicolumn{2}{|c|}{ Inoc/no $\mathrm{P}$ vs. $\mathrm{P}$} & $* *$ & $* *$ & $*$ & NS & NS & NS \\
\hline
\end{tabular}

${ }^{2}$ Measurements taken at the weeks presented represent significant height changes.

'Standard error of means based on error mean square from analysis of variance (41 df).

$\mathrm{N} \mathrm{S}, *, * *, * * *$ Nonsignificant or significant at $P=0.05,0.01$, or 0.001 , respectively. 
Table 2. Asparagus seedling growth response, after 26 weeks, to Glomus fasciculatum inoculation, in the presence or absence of supplemental P.

\begin{tabular}{|c|c|c|c|c|c|c|c|}
\hline \multirow[b]{2}{*}{ Inoculation } & \multirow{2}{*}{$\begin{array}{c}\mathrm{P} \\
\left(\mathrm{g} \cdot \mathrm{m}^{-3}\right)\end{array}$} & \multirow{2}{*}{$\begin{array}{c}\text { Fern ht } \\
\text { (Total/plant) }\end{array}$} & \multicolumn{2}{|c|}{$\begin{array}{l}\text { Fern wt } \\
\text { (g/plant) }\end{array}$} & \multicolumn{2}{|c|}{$\begin{array}{l}\text { Crown wt } \\
\text { (g/plant) }\end{array}$} & \multirow[b]{2}{*}{ Bud no. } \\
\hline & & & Fresh & Dry & Fresh & Dry & \\
\hline \multirow{2}{*}{$\overline{\text { Yes }}$} & 25 & 194 & 4.25 & 1.17 & 17.5 & 3.82 & 9.4 \\
\hline & 0 & 168 & 3.13 & 0.88 & 15.1 & 3.12 & 9.8 \\
\hline \multirow{2}{*}{ No } & 25 & 143 & 2.80 & 0.74 & 13.8 & 2.81 & 9.2 \\
\hline & 0 & 22 & 0.08 & 0.04 & 1.22 & 0.27 & 3.1 \\
\hline \multicolumn{2}{|l|}{$\mathrm{SE}^{\mathbf{z}}$} & 48 & 3.07 & 0.28 & 1.11 & 0.76 & 2.2 \\
\hline \multicolumn{2}{|l|}{ Infection correlation $y$} & 0.516 & & 0.626 & & 0.608 & 0.556 \\
\hline \multicolumn{8}{|l|}{ Significance } \\
\hline \multicolumn{2}{|l|}{ Inoc main effect } & *** & **** & $* * *$ & $* * *$ & *** & $* * *$ \\
\hline$P$, main effect & \multirow[b]{2}{*}{$:$} & $* * *$ & **** & **** & $* * *$ & *** & $* * *$ \\
\hline Inoc $\times \mathrm{P}$ & & $*$ & $*$ & $* * *$ & $* * *$ & $* * *$ & $* * *$ \\
\hline \multicolumn{2}{|c|}{ Inoc/P vs. inoc/no $\mathrm{P}$} & & * & * & NS & * & NS \\
\hline \multicolumn{2}{|c|}{ Inoc/P vs. non-inoc $/ \mathrm{P}$} & & ** & $m * *$ & ** & ** & NS \\
\hline \multicolumn{2}{|c|}{ Inoc/no $\mathrm{P}$ vs. non-inoc/P } & & NS & NS & NS & NS & NS \\
\hline \multicolumn{2}{|c|}{ Inoc $(P \&$ no $P)$ vs. non-inoc/P } & & * & ** & * & * & NS \\
\hline \multicolumn{2}{|c|}{$\mathrm{P}$ (Inoc \& nòn-inoc) vs. inoc/no $\mathrm{P}$} & & NS & NS & NS & NS & NS . \\
\hline
\end{tabular}

${ }^{2}$ Standard error of means based on error mean square from analysis of variance (41 df), ' $r$ value of correlations with percent root infection $(\mathrm{P}<0.001)$.

$\mathrm{NS}, *, * * * * *$ Nonsignificantorsignificant at $\mathrm{P}=0.05,0.01$, or 0.01$) 1$, respectively.

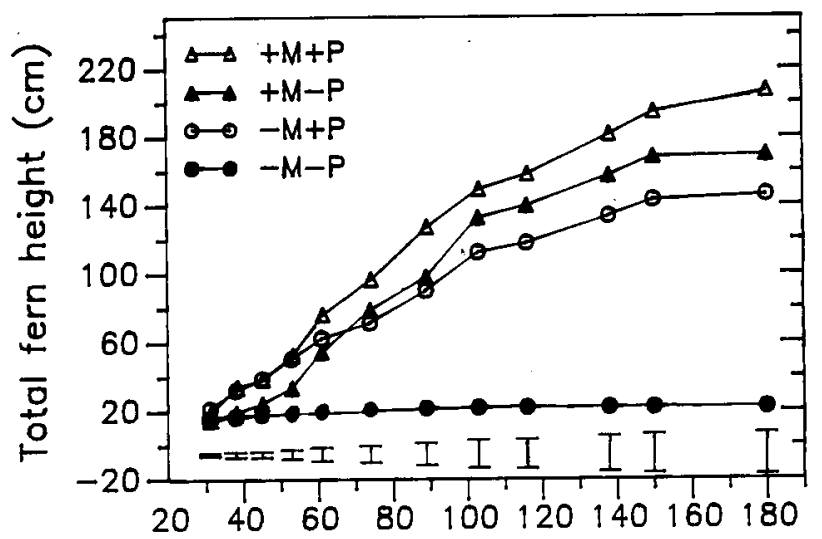

Fig. 1. Effect of inoculation with (Glomus fasciculatum and $25 \mathrm{~g} \mathrm{P} / \mathrm{m}^{3}$ on total fern height of seedling asparagus over time ( $+\mathrm{M}+\mathrm{P}=$ inoculated, $\mathrm{P}$-supplemented; $+\mathrm{M}-\mathrm{P}=$ inoculated, non-P-supplemented; $-\mathrm{M}+\mathrm{P}=$ noninoculated, $\mathrm{P}$-supplemented; $-\mathrm{M}-\mathrm{P}=$ noninoculated, non-P-supplemented; vertical lines represent SE).

light microscopy. A micrometer was used to measure the actual percent of root length in which hyphae, vesicles, or arbuscules of $G$. fascicdatum were present (Bierman and Linderman, 1981). To determine the number of G. fascicdatum spores present, soil surrounding the roots was removed, wet-sieved, and subjected to high-density sucrose centrifugation (Jenkins, 1964). Viability of the spores was not determined.

Analysis of variance was performed on the bi-weekly plant height measurements and on plant weights and infection percentages after 26 weeks; interaction between inoculation and P-supplementation was examined by means of specific planned contrasts. To detect possible growth pattern differences, linear regression curves were calculated for fern height over time, and differences in the regression curves of each of the four treatments were evaluated by analysis of variance of the regression coefficients (Snedecor and Cochran, 1980).

Beginning 8 weeks after planting, non-Psupplemented plants that were innoculated had significantly taller ferns than noninoculated plants. However, P-supplemented plants that were inoculated did not differ significantly in fern height from noninoculated plants until 11 weeks after planting (Table 1). Thus, it appears that P-supplementation lengthened the time required for $G$. fasciculatum to become established and functional. Hussey et al. (1984) noted increased fern growth after only 3 weeks in asparagus seedlings inoculated with G. versiforme and grown on Turface (calcined montmorillonite clay; International Minerals \& Chemicals, Des Plaines, Ill.). The difference between plant responses in our study and that of Hussey et al. (1984) may have been due to differences in growing medium, original growing medium fertility, original inoculum concentration, or to the use of different Glomus spp. The height differences between inoculated and noninoctdated plants, regardless of $\mathrm{P}$ supplementation, continued through the duration of the experiment.

After 26 weeks, plants inoculated with G. fasciculatum and grown in P-supplemented soil showed increased crown and fern weight, but not bud number (Table 2). In non-P-supplemented soil, inoculated plants had significantly greater heights, fern and crown weights, and bud numbers than noninoculated plants, which began to senesce after 12 weeks.

P-supplemented plants had greater $(P<$ $0.001)$ fern heights throughout the experiment (Table 1), and at 26 weeks had greater $(\mathrm{P}<0.001)$ fern and crown weights and bud numbers (Table 2 ), compared with non-Psupplemented seedlings. After 9 weeks, inoculation and P-supplementation treatments interacted significantly. Differences between P-supplemented and nonsupplemented inoculated plants became nonsignificant after 9 weeks (Tables 1 and 2). However, P-supplementation did not significantly increase growth of noninoculated plants throughout the experiment. While $\mathrm{P}$ supplementation did not affect final crown or fern characteristics of inoculated plants (Table 2), it was crucial for survival of noninoculated plants. After 26 weeks, noninoculated plants that were not $\mathrm{P}$ supplemented did not even have sufficient shoot tissue remaining for $\mathrm{P}$ tissue analysis.

Analysis of the regression curves of fern height over time revealed significantly different slopes for each of the four treatments, with inoculated, P-supplemented fern growth being most vigorous (Fig. 1).

Phosphorus supplementation of inoculated but not of noninoculated seedlings decreased $(\mathrm{P}<0.05)$ root infection and G. fasciculatum spore numbers (Table 3 ). This decrease in root infection in the presence of $\mathrm{P}$ is common (Miller et al., 1986). Superior fern and crown growth of the inoculated plants with supplemental $\mathrm{P}$ was probably due in part to the early growth response to $\mathrm{P}$ before the $\mathrm{G}$. fascictdatum became well-established. This positive response to $\mathrm{P}$ by mycorrhizal plants agrees with the findings of Chang (1985), who found that seedling growth was positively correlated with increasing levels of $P$ fertilization. After 10 weeks, noninoculated seedlings were smaller than inoculated, regardless of $P$ supplementation, suggesting that 
Table 3. Phosphorus levels and presence or absence of Glomus fasciculatum or hyphae in soil and in asparagus seedlings 26 weeks after inoculation.

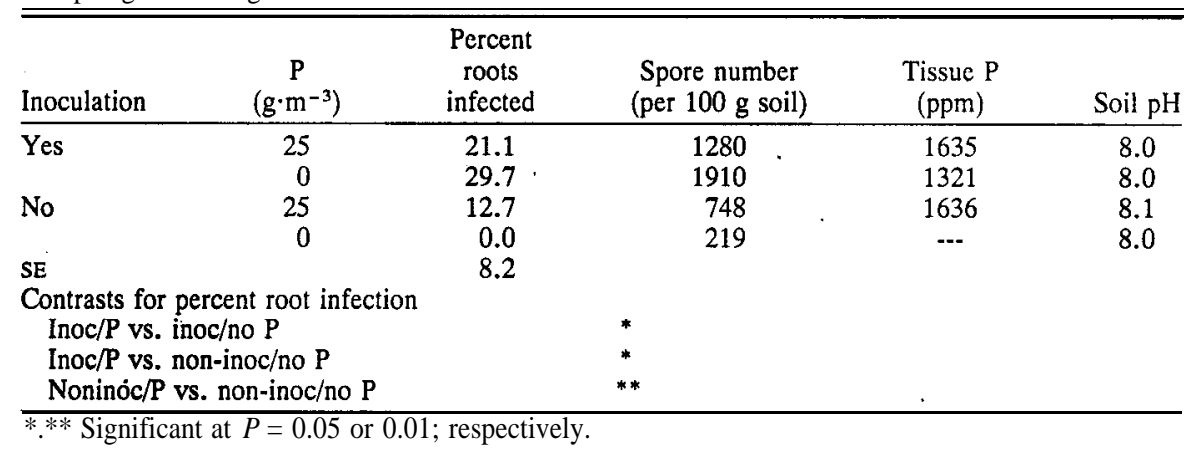

inoculation had a more-lasting effect than $\mathrm{P}$ supplementation. By the end of our study, $\mathrm{P}$ levels had decreased to 3 ppm in the P-supplemented media, compared to $1 \mathrm{ppm}$ in the nonsupplemented media.

Root infection assessment revealed an average infection rate of $12.7 \%$ in the noninoculated P-supplemented treatment. Since the soil was pasteurized and the infection was by $G$. fasciculatum, we believe the contamination occurred after planting, on the greenhouse bench, where the inoculated and noninoculated treatments were in close proximity, randomly arranged. It is probable that the contamination occurred late in the study, as the G. fasciculatum in this treatment exhibited less vesicle and arbuscule development than in inoculated plants, though there were extensive hyphal networks in some roots. Also, no root infection was observed in noninoculated, non-P-supplemented plants, even though spores of $G$. fasciculatum were collected from their soil (Table 3 ). This again suggests that contamination occurred late in the study, when the weakened, noninoculated, non-P-supplemented plants lacked the ability to support mycorrhizal infection.

Frank et al. (1987) reported partially contaminated controls, and also found the percentage of mycorrhizal infection to be substantially lower in the noninoculated plants than in those deliberately inoculated. Furthermore, it was noted that there was a highly significant effect of deliberate inoculation on plant growth response, as we have noted here. Others reporting contaminated controls (Crush and Pattison, 1975; Jensen, 1984; Maronek et al., 1980) have observed this significant positive host-plant response to deliberate inoculation.
Correlations between percentage of roots infected and growth of individual plants showed a positive influence $(P=0.001)$ of infect ion, regardless of the initial inoculum source (Table 2). Thus, the significantly lower plant growth response of the contaminated treatment was almost certainly due to the lower percentage of actual root colonization to inoculated treatments.

This study adds to the evidence that inoculation with Glomus spp. enhances seedling asparagus growth. We suggest that initial $P$ levels of the potting medium maybe most important during the initial establishment period of G. fasciculatum in asparagus seedlings, after which the fungus begins to use $P$ unavailable to non-mycorrhizal plants. Further research should be focused on identifying sequential $\mathrm{P}$ levels optimal for both asparagus seedling vigor and VAM development.

\section{Literature Cited}

Allen, E.B. and G.L. Cunningham. 1983. Effects of vesicular-arbuscular mycorrhizae onDistichlis spicata under three salinity levels. New Phytol. 93:227-236.

Bierman, B.J. and R.G. Linderman. 1981. Quantifying vesicular-arbuscular mycorrhizae: a proposed method towards standardization. New Phytol. 87:63-67.

Chang, D.C.N. 1985. Responses of asparagus seedlings to three Glomus endomycorrhizal fungi. Proc. of 6th North Amer. Conf. on Mycorrhizae, Bend, Ore., July 25-29, 1984. p. 36.

Crush, J.R. and A.C. Pattison. 1975. Preliminary results on the production of vesicular-arbuscular mycorrhizal inoculum by freeze drying, $\mathrm{p}$. 485493. In: F.E. Sanders, M. Mosse, and B.B. Tinker (eds.). Endomycorrhizas. Academic, New York.
Daniels, B.A. and J.A. Menge. 1981. Evaluation of the commercial potential of the vesiculararbuscular mycorrhizal fungus, Glomus epigaeus. New Phytol. 87:345-354.

Dehne, H.W. 1982. Interaction between vesicular-arbuscular mycorrhizal fungi and plant pathogens. Phytopathology 72:1115-1119.

Frank, J. B., A.M. Petrovic, and K.W. Mudge. 1987. Influence of inoculum placement depth on endomycorrhizal fungal infection and perennial ryegrass shoot growth. J. Amer. Soc. Hort. Sci. 112:282-286.

Hayman, D.S. 1983. The physiology of vesicular-arbuscular endomycorrhizal symbiosis. Can. J. Bet. 61:944-963.

Hussey, R. Blaine, R.L. Peterson, and H. Ticssen. 1984. Interactions between vesicular-arbuscular mycorrhizal fungi and asparagus. Plant \& Soil 79:403-416.

Jenkins, W.R. 1964. A rapid centrifugal flotation technique for separating nematodes from soil. Plant Dis. Rptr. 48:692.

Jensen, A. 1984. Responses of barley, pea, and maize to inoculation with different vesiculararbuscular mycorrhizal fungi in irradiated soil. Plant \& Soil 78:315-323.

Maronek, D. M., J. W. Hendrick, and J. Kiernan, 1980. Differential growth response to the my. corrhizal fungus Glomus fasciculatus of South. ern Magnolia and Bar Harbor Juniper grown in containers in composted hardwood bark-shale. J. Amer. Soc. Hort. Sci. 105:206-208.

Miller, C. J., Jr., S. Rajapakse, and R.K. Garber. 1986. Vesicular-arbuscular mycorrhizae in vegetable crops. HortScience 21(4):974-984,

Phillips, J.M. and D.S. Hayman. 1970. Improved procedures for clearing and staining parasitic and vesicular-arbuscular mycorrhizal fungi for rapid assessment of infection. Trans. Brit. Mycol. Soc. 55:158-161.

Plenchette, C., V. Furlan, and J.A. Fortin. 1982. Effects of different endomycorrhizal fungi on five host plants grown on calcined montmorillonite clay. J. Amer. Soc. Hort. Sci. 107:535538.

Rhodes, L.H. and J.W. Gerdemann. 1980. Nutrient translocation in vesicular-arbuscular mycorrhizae, p. 174-195. In: C.B. Cook, P.W. Pappas and E.D. Rudolph) (eds.). Cellular interactions in symbiosis and parasitism. Ohio State Univ. Press, Columbus.

Safir, G. R., J.S. Boyer, and J.W. Gerdemann. 1971. Mycorrhizae enhancement of water transport in soybean. Science 172:581-583.

Snedecor, C.W. and W.G. Cochran. 1980. Statistical methods, 7th ed. Iowa State Univ. Press, Ames.

Wacker, T. L., G.R. Safir, and C.T. Stephens. 1987. Effect of vesicular-arbuscular mycorrhizae and phosphorus fertilization on growth and disease severity in asparagus. Phytopathology 77(12):1760. (Abstr.) 